\title{
Carcinoma epidermoide sobre hidradenitis supurativa: a propósito de un caso
}

\section{Squamous cell carcinoma arising in hidradenitis suppurativa: a case report}

\author{
Isabel Gainza-Apraiz ${ }^{1 *}$, Ane Lobato-Izagirre ${ }^{1}$, Nerea González-Romero ${ }^{1}$, Mikel Meruelo-Ruano ${ }^{1}$, \\ Mireya Lázaro-Serrano ${ }^{2}$ y Rosa $\mathrm{M}^{a}$ Izu-Belloso ${ }^{1}$ \\ ${ }^{1}$ Servicio de Dermatología, Hospital Universitario Basurto, Bilbao; ${ }^{2}$ Servicio de Dermatología, Hospital Universitario Araba, Vitoria-Gasteiz, País Vasco. España
}

\section{Resumen}

Introducción: La hidradenitis supurativa (HS) es una dermatosis inflamatoria crónica que afecta a la unidad pilosebácea en las grandes áreas intertriginosas. La inflamación crónica de larga evolución favorece el desarrollo del carcinoma de células escamosas (CCE) sobre lesiones de HS. Esta complicación es más frecuente en varones y en las regiones glútea o perineal. Caso clínico: Varón de 57 años con HS grave (Hurley III) con >30 años de evolución, de predominio en glúteos y resistente a múltiples tratamientos; desarrolló un carcinoma epidermoide infiltrante sobre lesiones de HS. Al momento del diagnóstico mostraba adenopatías locorregionales de gran tamaño. Se descartó el tratamiento quirúrgico o radioterápico y se trató con quimioterapia paliativa. Discusión: La infección por el virus del papiloma humano (HPV) y otros cofactores parecen intervenir en la transformación maligna de las lesiones. El retraso diagnóstico y una alta capacidad de proyectar metástasis le confieren al carcinoma epidermoide sobre la HS un mal pronóstico y elevada mortalidad. Conclusión: Ante una HS avanzada, de larga evolución y resistente al tratamiento, sobre todo si asienta en la región glútea, se deben tomar múltiples biopsias profundas para detectar de manera temprana el desarrollo de un posible carcinoma epidermoide sobre las lesiones.

Palabras clave: Hidradenitis supurativa. Tumores malignos. Carcinoma epidermoide

\section{Abstract}

Introduction: Hidradenitis suppurativa (HS) is a chronic inflammatory skin condition that affects the folliculosebaceous unit in large intertriginous body areas. Longstanding inflammation might lead to the development of a squamous cell carcinoma arising in HS lesions, which is more likely to occur in males and at the gluteal or perineal sites. Case report: A 57-year-old man with an over 30-year history of severe HS (Hurley III) involving the buttocks and refractory to a wide variety of treatments developed a squamous cell carcinoma over HS lesions. He presented large locoregional lymphadenopathies at diagnosis. Surgery and radiotherapy were dismissed and he was treated with palliative chemotherapy. Discussion: Human papillomavirus (HPV) and other cofactors seem to be involved in the malignant transformation of the lesions. Due to the common delayed diagnosis and its high metastatic ability, prognosis is poor and mortality rates high. Conclusion: Areas of non-healing wounds should be cautiously observed and multiple deep biopsies carried out in patients suffering from longstanding and resistant HS, especially if they involve the buttocks or perineum, in order to detect the development of a squamous cell carcinoma arising in HS lesions at an early stage.

Key words: Hidradenitis suppurativa. Malignant tumors. Squamous cell carcinoma
Correspondencia:
Fecha de recepción: 29-05-2020
Fecha de aceptación: 21-08-2020
*Isabel Gainza-Apraiz
DOI: 10.24875/MCUT.20000020
Disponible en internet: 16-07-2021 Med Cutan Iber Lat Am. 2021;49(2):104-109 www.MedicinaCutanealLA.com 0210-5187/@ 2020 Colegio Ibero Latinoamericano de Dermatología A.C. (CILAD). Publicado por Permanyer. Este es un artículo open access bajo la licencia CC BY-NC-ND (http://creativecommons.org/licenses/by-nc-nd/4.0/). 


\section{Introducción}

La hidradenitis supurativa (HS) es una dermatosis inflamatoria crónica con una prevalencia de $1 \%$ en la población general ${ }^{1-3}$ y $4 \%$ en la población joven ${ }^{2}$ (es menor en diversos estudios $\left.{ }^{4-6}\right)$. Es más frecuente en mujeres, con una relación de 3:1 con respecto a los hombres ${ }^{3}$ y suele comenzar tras la pubertad; su actividad máxima ocurre entre los 20 y 40 años?

Hasta fecha reciente se pensaba que la HS afectaba a las glándulas apocrinas, pero en la actualidad se postula que lesiona al folículo pilosebáceo. Las lesiones comienzan con una hiperqueratosis y taponamiento folicular, lo que da lugar a una dilatación de la unidad pilosebácea, con la consiguiente rotura y salida del contenido folicular a la dermis que desencadena una respuesta inflamatoria local ${ }^{1}$.

El mal control de la respuesta inflamatoria y la relación de la HS con diversas enfermedades autoinmunitarias y autoinflamatorias indican que la enfermedad se debe a un desequilibrio del sistema inmunitario en personas genéticamente predispuestas ${ }^{1}$. Un $40 \%$ de los pacientes tiene algún miembro en la familia afectado y el patrón de herencia mayoritario es el autosómico dominante con penetrancia variable ${ }^{8}$. Entre los factores inmunológicos se ha estudiado la elevación de la interleucina $1 \beta$ y del factor de necrosis tumoral $\alpha$, alteraciones en el microbioma y biopelícula en los folículos pilosos y fístulas ${ }^{9}$.

Diversos factores exógenos pueden desencadenar 0 agravar la $\mathrm{HS}^{1}$, entre ellos el tabaco $(70 \%-89 \%$ de los pacientes fuman). La nicotina estimula la sobreproducción de interleucina 10 y se relaciona con la disfunción de la vía de señalización de la $\gamma$-secretasa y Notch, claves en la patogenia de la $\mathrm{HS}^{1}$. La obesidad, por la irritación mecánica y maceración que produce, es también exacerbadora, al igual que la ropa ajustada, la depilación o los desodorantes ${ }^{10}$. Por último, dado el predominio femenino, inicio tras la pubertad, brotes premenstruales y mejoría durante la gestación o tras la menopausia, se presupone que el hiperandrogenismo podría participar en su patogenia. No obstante, los análisis hormonales y la ausencia de respuesta terapéutica esperada con tratamientos anticonceptivos no sustentan esta hipótesis ${ }^{1}$.

Los abscesos, fístulas y nódulos se localizan en las grandes áreas intertriginosas y son más frecuentes en la región inframamaria, axilar e inguinal en mujeres y en los glúteos y zona perianal en hombres ${ }^{1,11}$. Los brotes cursan con dolor y supuración, y tienden a mejorar

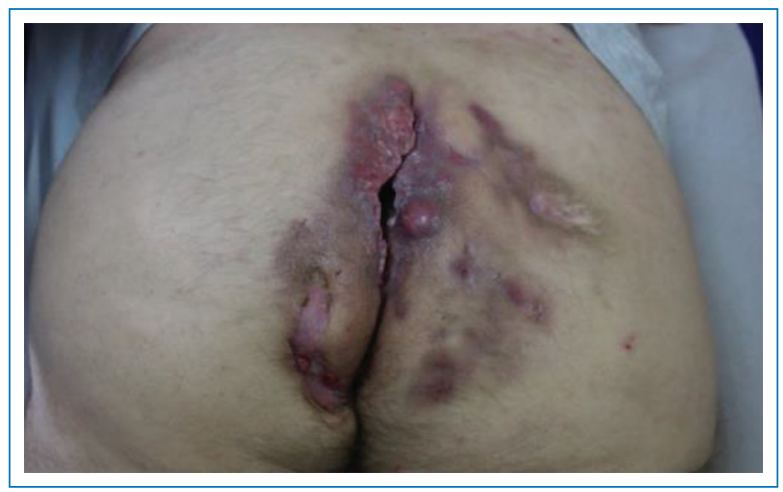

Figura 1. Hidradenitis supurativa grave (estadio III de Hurley) en las regiones glútea y perianal.

de forma espontánea en siete a 10 días. La gravedad de las lesiones tiende a ser mayor en los hombres ${ }^{1,12}$.

Estos pacientes sufren múltiples comorbilidades ${ }^{12}$ (obesidad $^{6}$, síndrome metabólico, síndrome de ovario poliquístico $0^{6}$, enfermedad inflamatoria intestinal ${ }^{9}$, pioderma gangrenoso y depresión, entre otros) y un notable estigma social, lo que se refleja en una menor calidad de vida².

Por último, se han descrito casos de carcinoma epidermoide (CE) que se desarrolla sobre lesiones de HS, que es una complicación rara con menos de 100 casos informados en las publicaciones médicas ${ }^{13,14}$. La mayor parte de estos carcinomas se localiza en las regiones glútea, perianal y perineal ${ }^{11-14}$ y son más frecuentes en hombres, con una proporción de 5-6.75:111,15. Esta malignización ocurre en la HS avanzada y de larga evolución, y transcurre 26 a 28.5 años desde el diagnóstico de la HS hasta el desarrollo del CE ${ }^{13,15,16}$. La edad media al diagnóstico de la HS es de 27 años y la del CE sobre HS de 52 a 54 años $^{15,16}$.

\section{Caso clínico}

Varón de 57 años, fumador y con sobrepeso, que presenta lesiones de HS grave (Hurley III) en la región glútea desde 33 años antes (Fig. 1), con resistencia a múltiples tratamientos. Se había tratado con numerosas pautas de antibióticos tópicos y sistémicos y sometido a varias intervenciones quirúrgicas. Asimismo, se probó tratamiento con corticoides, metotrexato y diferentes fármacos biológicos (adalimumab, infliximab y ustekinumab).

Aun así, persistía intensa supuración y mal control del dolor; en consecuencia, todavía bajo tratamiento con ustekinumab, se lo sometió a reintervención 


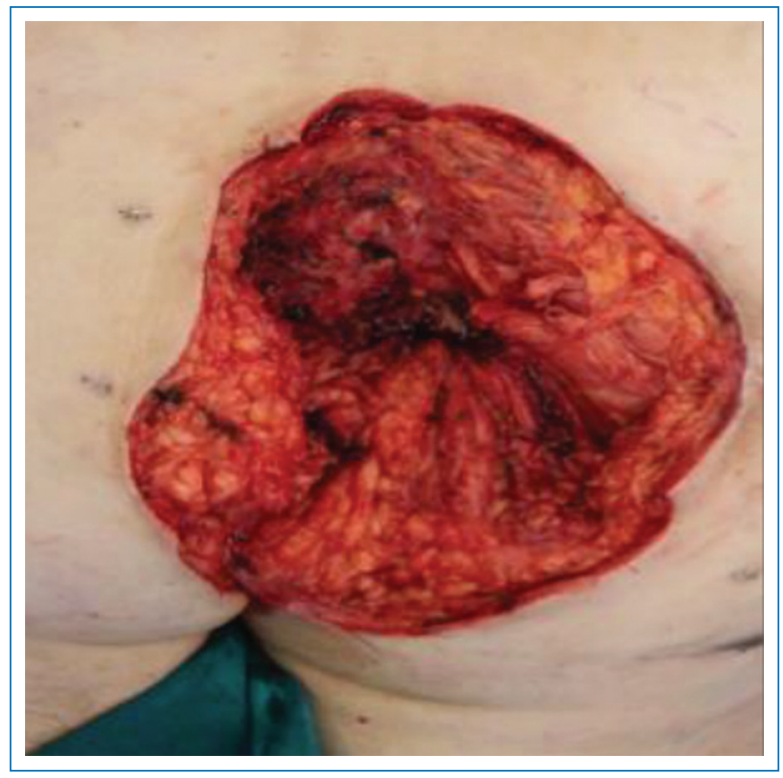

Figura 2. Intervención quirúrgica para la exéresis de los trayectos fistulosos.

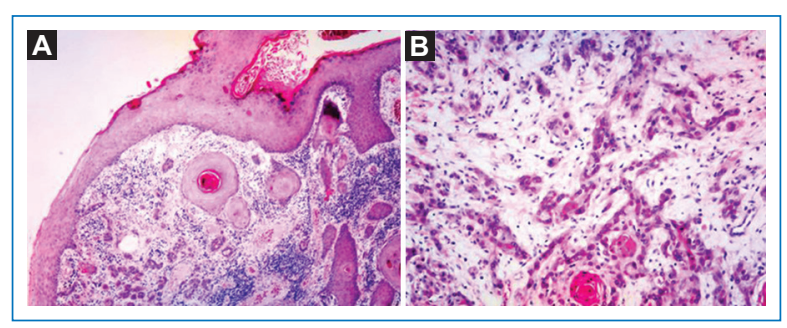

Figura 3. Anatomía patológica de la lesión. A: carcinoma epidermoide queratinizante (perlas córneas).

B: carcinoma epidermoide infiltrante (atraviesa la membrana basal).

quirúrgica y exéresis de los trayectos fistulosos (Fig. 2). La anatomía patológica de la muestra arrojó el resultado de un CE ulcerado, queratinizante e infiltrante, sobre las lesiones de HS a nivel glúteo, con marcados cambios inflamatorios adjuntos (Fig. 3 y 4).

Se realizó la genotipificación de HPV, que resultó negativo para los siguientes tipos de bajo $(6,11,32,40$, $42,44,54,55,61,62,64,71,72,74,81,83,84,87,89$, 91) y alto $(16,18,26,31,33,35,39,45,51,52,53,56$, $58,59,66,67,68,69,70,73,82,85)$ riesgo oncogénico. El estudio inmunohistoquímico mostró positividad focal para el P-16 en células aisladas (Fig. 5).

El estudio de extensión por imagen de tomografía axial computarizada (TAC) mostró adenopatías locorregionales inguinales e iliacas de gran tamaño. Se realizó

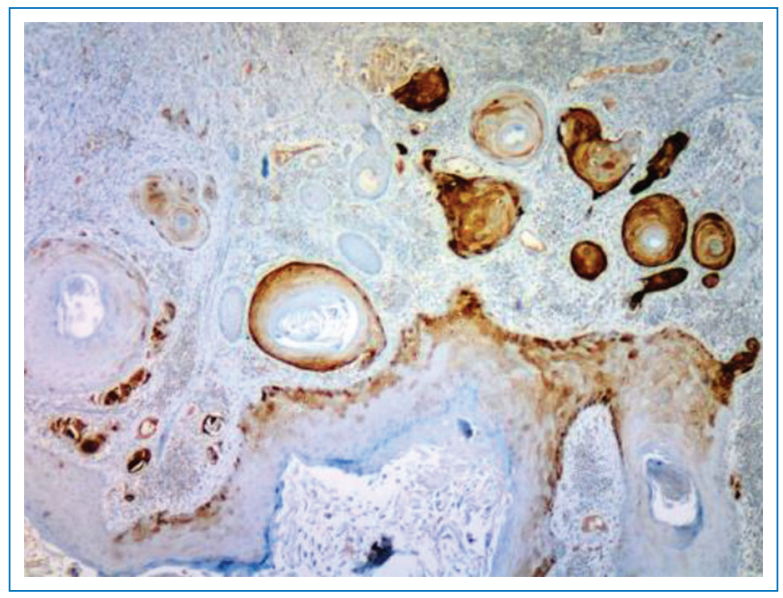

Figura 4. Tinción inmunohistoquímica de la muestra, con positividad focal para P-16.

biopsia por aguja gruesa de la adenopatía inguinal izquierda, que reveló infiltración por CE queratinizante moderadamente diferenciado. Estos hallazgos se observaron también en la tomografía por emisión de positrones-tomografía axial computarizada (TEP-TAC), en la que se hallaron más ganglios locorregionales indicativos de malignidad, así como implantes tumorales en tejido subcutáneo pélvico izquierdo y músculo glúteo derecho, y un incremento de la actividad metabólica sobre tejidos blandos y óseos pericoccígeos, sin poder descartar que correspondieran a tejido neoplásico.

El comité de tumores del hospital valoró el caso y se desestimó para tratamiento quirúrgico por su tamaño y localización de adenopatías. También se contraindicó la radioterapia radical por tratarse de un campo demasiado extenso, por lo que se decidió iniciar tratamiento con quimioterapia paliativa con cisplatino y 5 -fluoruracilo. No obstante, el paciente falleció menos de seis meses después del diagnóstico del CE.

\section{Discusión}

El desarrollo de CE sobre lesiones de HS es una complicación infrecuente, pero clínicamente relevante por las implicaciones sobre el pronóstico del proceso. Se han postulado diferentes mecanismos patogénicos por los que las lesiones de HS podrían derivar en CE.

En primer lugar, los estados de inflamación crónica producen un microentorno que favorece la oncogénesis. Se trata de entornos sometidos a alto estrés y daño tisular. La respuesta inmunitaria que se produce ante estos estímulos genera radicales libres de oxígeno que infligen un daño oxidativo al DNA, lo que provoca 


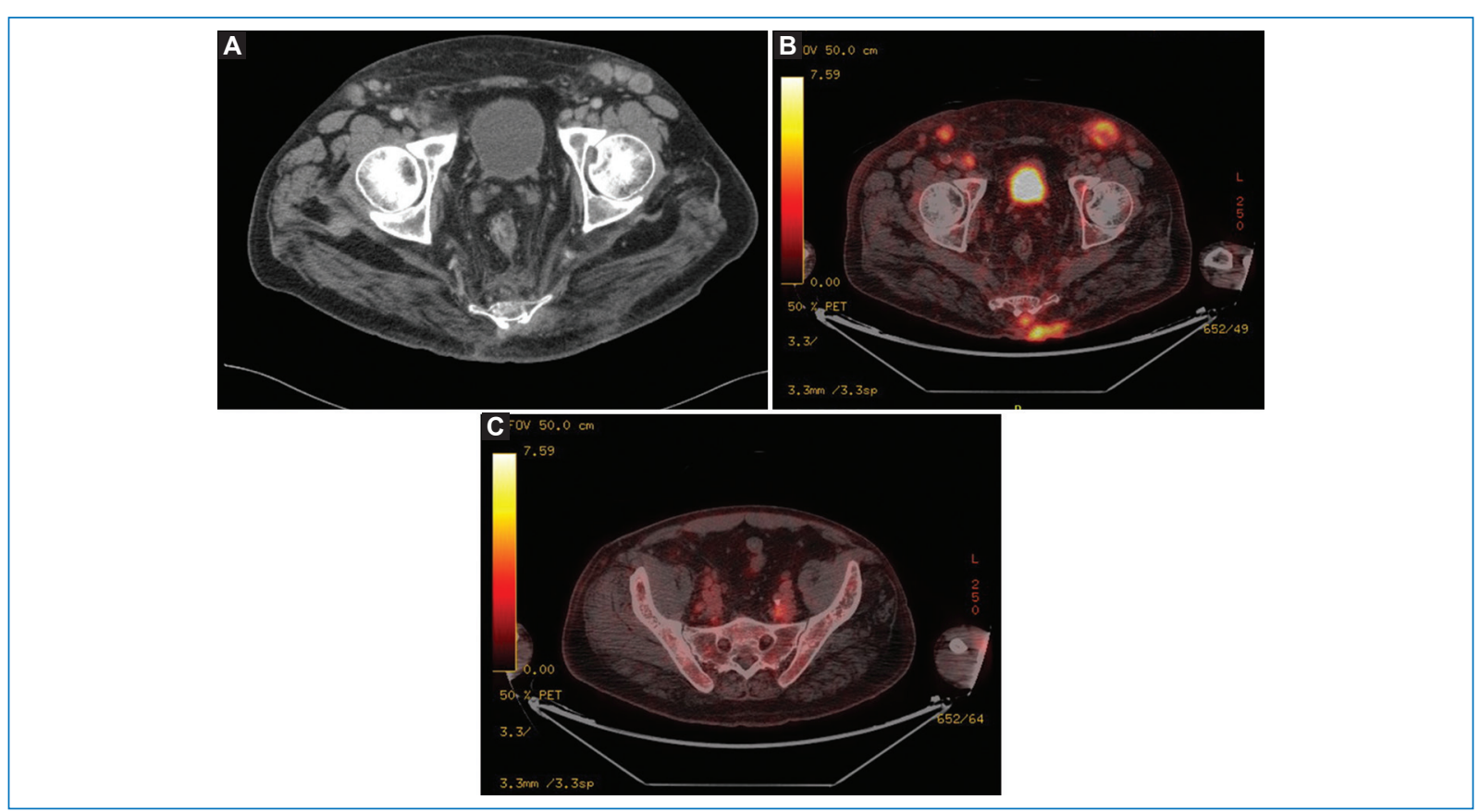

Figura 5. A: estudio de extensión mediante TAC. B-C: PET-TAC, observándose adenopatías iliacas e inguinales bilaterales. En el PET-TAC existe además un aumento de captación de glucosa a nivel sacro-coxígeo, sugestivo de enfermedad neoplásica residual postquirúrgica.

mutaciones que se escapan al control de genes supresores de tumores y reparadores de DNA ${ }^{16,17}$.

Además, las regiones afectadas de HS de larga evolución se vuelven inmunológicamente vulnerables. Los episodios recurrentes de inflamación y cicatrización bloquean y destruyen las vías de drenaje linfático y el linfedema es una secuela común de la HS glútea y anogenital. Esto dificulta la llegada de células inmunocompetentes a la zona, lo que da origen al denominado distrito cutáneo inmunocomprometido, incapaz de soportar las agresiones y lo que favorece el desarrollo infecciones y tumores ${ }^{14,17}$.

Por otro lado, defectos adquiridos o heredados en la vía de señalización Notch juegan un papel importante. La hiperactividad de Notch resulta en una excesiva producción pilosa y la formación de quistes epidérmicos a partir de estos folículos, con la consiguiente ruptura folicular. Además, Notch actúa como supresor de tumores en cáncer cutáneo distinto del melanoma, incluido el $\mathrm{CE}^{16}$. En fecha reciente se ha confirmado el papel de los genes PSENEN, PSEN1 y NCSTN en la patogenia de la HS familiar, que codifican componentes esenciales de la vía $\gamma$-secretasa, que interviene en la regulación de la vía Notch. Las alteraciones en esta vía inhiben la generación de células citolíticas y producen una inmunidad innata insuficiente, lo que prolonga la actividad inflamatoria. La HS familiar suele ser más grave que la esporádica ${ }^{11}$.

Se cree que el HPV podría jugar un papel importante en el desarrollo del CE en pacientes con HS anogenital, lo que explicaría que esta complicación sea más frecuentes en hombres ${ }^{17,18}$. Lavogiez, et al, ${ }^{19}$ investigaron la presencia del HPV en ocho tumores anogenitales mediante PCR (reacción en cadena de la polimerasa), con resultado positivo en todas las muestras para genotipos de bajo (HPV 6) y alto (HPV 16 y 68) riesgo oncogénico. En fecha reciente se ha descubierto que los genotipos de bajo riesgo pueden participar en el desarrollo de CE en la región anogenital. Jourabchi, et al, ${ }^{20}$ encontraron que entre los pacientes con HS de larga evolución que desarrollaban CE, 73\% era positivo para $\alpha$-HPV y $88 \%$ para $\beta$-VPH. Por otro lado, la piel afectada de HS en estadio III de Hurley carece de defensinas y otros péptidos antipatogénicos importantes para combatir el HPV ${ }^{11}$. Sin embargo, no es claro si la degeneración maligna de las lesiones ocurre con mayor frecuencia en la región glútea o perianal por el HPV ${ }^{17,18}$.

La genotipificación del HPV fue negativa en este paciente y la tinción inmunohistoquímica para la P-16 positiva. En realidad, esta proteína supresora de tumores puede alterarse en numerosos tumores mediante 
anomalías genéticas o epigenéticas, sin que exista una infección oncogénica por el HPV ${ }^{21}$.

Muchos de los pacientes con HS grave se encuentran en tratamientos biológicos con fármacos anti-TNF, que al atenuar la respuesta inmunitaria para reducir la inflamación también supondrían un riesgo para la adquisición del HPV y el desarrollo de infecciones y tumores ${ }^{16}$. Se han descrito casos de pacientes en tratamiento con estos fármacos que desarrollan $C E^{18}$, por lo que se ha postulado que estos tratamientos podrían favorecer la malignización de las lesiones. Sin embargo, se trata de pacientes con una inmunidad subyacente muy alterada, por lo que resulta controvertido si estos fármacos juegan en verdad un papel en el desarrollo de los carcinomas ${ }^{11}$.

Por último, el humo del tabaco contiene sustancias químicas que interactúan con los receptores nicotínicos de acetilcolina y de aril hidrocarburos en los queratinocitos, que inducen hiperplasia epitelial, acantosis y cornificación. Además, activan a los fibroblastos y células inmunitarias, que secretan más citocinas proinflamatorias $^{16}$. La nicotina estimula la sobreproducción de IL-10, se relaciona con la disfunción de la vía de señalización de la $\gamma$-secretasa y Notch y promueve el taponamiento folicular a través de la quimiotaxia de neutrófilos, lo que incrementa la inflamación crónica y favorece el desarrollo del $\mathrm{CE}^{16}$. En realidad, hasta el $80 \%$ de los pacientes que desarrollan un CE sobre HS crónica es fumador ${ }^{20}$.

En el contexto de una hidradenitis muy avanzada, con inflamación, ulceración y cicatrización marcadas, puede resultar complicado distinguir en clínica el área de malignización ${ }^{15,16,18,22}$, lo que repercute de manera negativa en un diagnóstico temprano. Por ello debe considerarse un posible desarrollo un CE en áreas de HS de larga evolución que no sanan y no responden al tratamiento ${ }^{23}$, en especial en varones con afectación glútea o perineal.

Las biopsias cutáneas, sobre todo si son superficiales, muestran con frecuencia falsos negativos, ya que el tumor se extiende en profundidad a través de fístulas y trayectos subcutáneos. Para impedir un mayor retraso diagnóstico, las biopsias deben ser múltiples y profundas $^{15,24}$.

Los CE que se desarrollan sobre áreas de inflamación crónica producidas por la HS son histológicamente bien diferenciados. Sin embargo, poseen una tasa de replicación elevada, crecimiento rápido, agresividad local, diseminación temprana en profundidad y alta capacidad de metastizar, lo que les confiere muy mal pronóstico ${ }^{16,18}$ junto con el diagnóstico tardío. Hasta el $50 \%$ de los pacientes fallece en los primeros dos años tras la detección del carcinoma ${ }^{15}$.

\section{Conclusión}

El desarrollo de CE sobre lesiones de HS es una complicación infrecuente que conlleva muy mal pronóstico. Ante una HS avanzada, de larga evolución y resistente a múltiples tratamientos, sobre todo si asienta en la región glútea y muestra inflamación y ulceración notorias, se deben tomar múltiples biopsias profundas con el fin de identificar de manera temprana el desarrollo de un posible CE sobre las lesiones.

\section{Financiamiento}

Los autores declaran no haber recibido financiamiento para este estudio.

\section{Conflicto de intereses}

Los autores declaran no tener conflicto de intereses.

\section{Responsabilidades éticas}

Protección de personas y animales. Los autores declaran que para esta investigación no se han realizado experimentos en seres humanos ni en animales.

Confidencialidad de los datos. Los autores declaran que han seguido los protocolos de su centro de trabajo sobre la publicación de datos de pacientes.

Derecho a la privacidad y consentimiento informado. Los autores han obtenido el consentimiento informado de los pacientes y/o sujetos referidos en el artículo. Este documento obra en poder del autor de correspondencia.

\section{Bibliografía}

1. Jemec GB, Heidenheim M, Nielsen NH. The prevalence of hidradenitis suppurativa and its potential precursor lesions. J Am Acd Dermatol. 1996;35:191-4.

2. Revuz JE, Canoui-Poitrine F, Wolkenstein P, Viallete C, Gabison G, Pouget $F$, et al. Prevalence and factors associated with hidradenitis suppurativa: results from two case-control studies. J Am Acd Dermatol. 2008;59:596-601.

3. Martorell A, García-Martínez FJ, Jiménez-Gallo D, Pascual JC, Pereyra-Rodríguez J, Salgado L, et al. Actualización en hidradenitis supurativa (I): epidemiología, aspectos clínicos y definición de la enfermedad. Actas Dermo-Sifilográficas [Internet]. 2015;106(9):703-15.

4. Shahi V, Alikhan A, Vázquez BG, Weaver Al, Davis MD. Prevalence of hidradenitis suppurativa: a population-based study in Olmsted County, Minnesota. Dermatology. 2014;229:154-8.

5. Cosmatos I, Matcho A, Weinstein R, Montgomery MO, Stang P. Analysis of patient claims data to determine the prevalence of hidradenitis suppurativa in the United States. J Am Acad Dermatol. 2013;68:412-9.

6. Shlyankevich J, Chen AJ, Kim GE, Kimball AB. Hidradenitis suppurativa is a systemic disease with substantial comorbidity burden: a chart-verified case-control analysis. J Am Acad Dermatol. 2014;71:1144-50.

7. Von der Werth JM, Williams HC. The natural history of hidradenitis suppurativa. J Eur Acad Dermatol Venereol. 2000;14:389-92. 
8. Wang B, Yang W, Wen W, Sun J, Su B, Liu B, et al. Г-secretase gene mutations in familial acné inversa. Science. 2010;19:330,1065.

9. Van Der Zee HH, Laman JD, Boer J, Prens EP. Hidradenitis suppurativa: viewpoint on clinical phenotyping, pathogenesis and novel treatments. Exp Dermatol. 2012;21:735-9.

10. Magesson LJ, Danby FW. Hidradenitis suppurativa. Best Pract Res Clin Obstet Gynaecol [Internet]. 2014;28:1013-27.

11. Scheinfeld N. A case of a patient with stage III familial hidradenitis suppurativa treated with 3 courses of infliximab and died of metastasic squamous cell carcinoma. Dermatology Online Journal. 2014;20(3):17.

12. Kohorst JJ, Kimball AB, Davis MDP. Systemic associations of hidradenitis suppurativa. Journal of the American Academy of Dermatology [Internet]. 2015;73(5):S27-35.

13. Nagappan P. Mortality high in squamous cell carcinoma in hidradenitis suppurativa. Dermatology Times. 2018;39(12).

14. Fabbrocini G, Ruocco E, De Vita V, Monfrecola G. Squamous cell carcinoma arising long-standing hidradenitis suppurativa: an overlooked facet of the immunocompromised district. Clinics in Dermatology. 2017;35: 225-227.

15. Huang C, Lai Z, He M, Zhai B, Zhou L, Long X. Successful surgica treatment for squamous cell carcinoma arising from hidradenitis suppurativa. A case report and literature review. Medicine. 2017:96:3 (e5857).

16. Chapman S, Delgadillo D, Barber C, Khachemoune A. Cutaneous squamous cell carcinoma complicating hidradenitis suppurativa: a review of the prevalence, pathogenesis and treatment of this dreaded complication. Acta Dermatovenereologica. 2018;27:25-28.
17. De Vita V, Ruocco E. Letter to the Editor referring to Hessam, et al. Squamous cell carcinoma arising in hidradenitis suppurativa: subclinical lymphedema may have favoured the tumor onset. Journal of the German Society of Dermatology. 2017;1601-0379.

18. Segura-Palacios JM, García-Montero P, Fúnez-Liébana R, Repiso-Jiménez JB. Human papilloma virus and the risk of squamous cell carcinoma arising in hidradenitis suppurativa. Actas Dermosifiliogr. 2018;109:457-459.

19. Lavogiez C, Delaporte E, Darras-Vercrambe S. Clinicopathological study of 13 cases of squamous cell carcinoma complicating hidradenitis suppurativa. Dermatology. 2010;220:147-53.

20. Jourabchi N, Fischer AH, Cimino-Mathews A, Waters KM, Okoye GA. Squamous cell carcinoma complicating a chronic lesion of hidradenitis suppurativa: a case report and review of the literature. Int Wound J. 2017;14:435-438.

21. Hodgson A. Stains p16 INK4a. [Internet]. Michigan: PathologyOutlines 2000 [revisado enero 2018; citado enero 2019]. Disponible en: http:/l www.pathologyoutlines.com/topic/stainsp16.html

22. Pitch MA, Bryan DJ, McMillan J, Chavez L, Hammes SR, Scott G, Mercurio MG. Somers KE. A fatal case of parathyroid hormone-related peptide (PTHrP)-producing squamous cell carcinoma arising in the context of long-standing hidradenitis suppurativa. JAAD Case Reports. 2018:4:426-428.

23. Harview C, Truong A, Worswick S, Sarantopoulos G, Hsiao J. Squamous cell carcinoma of the perineum masquerading as necrotizing hidradenitis suppurativa. Dermatology Online Journal. 2018;24(4):12.

24. Shukla VK, Hughes LE. A case of squamous cell carcinoma complicating hidradenitis suppurativa. European Journal of Surgical Oncology. 1995;21:106-109. 